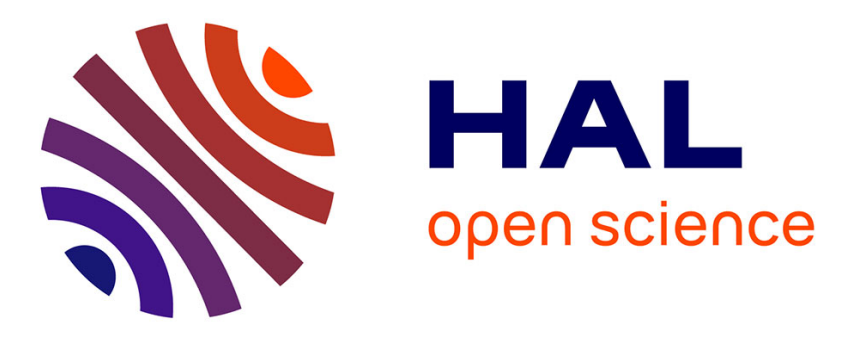

\title{
Transition State Spectroscopy of the Photoinduced Ca + CH3F Reaction. 2. Experimental and Ab Initio Studies of the Free Ca***FCH3 Complex
}

J.-M. Mestdagh, Fernand Spiegelman, Eric Gloaguen, M. Collier, F. Lepetit, M.-A. Gaveau, C. Sanz Sanz, B. Soep

\section{To cite this version:}

J.-M. Mestdagh, Fernand Spiegelman, Eric Gloaguen, M. Collier, F. Lepetit, et al.. Transition State Spectroscopy of the Photoinduced Ca + CH3F Reaction. 2. Experimental and Ab Initio Studies of the Free Ca***FCH3 Complex. Journal of Physical Chemistry A, 2006, 110, pp.7355-7363. 10.1021/jp057483j . hal-00126680

\section{HAL Id: hal-00126680 \\ https://hal.science/hal-00126680}

Submitted on 25 Jan 2007

HAL is a multi-disciplinary open access archive for the deposit and dissemination of scientific research documents, whether they are published or not. The documents may come from teaching and research institutions in France or abroad, or from public or private research centers.
L'archive ouverte pluridisciplinaire HAL, est destinée au dépôt et à la diffusion de documents scientifiques de niveau recherche, publiés ou non, émanant des établissements d'enseignement et de recherche français ou étrangers, des laboratoires publics ou privés. 


\title{
Transition state spectroscopy of the photoinduced $\mathrm{Ca}+\mathrm{CH}_{3} \mathrm{~F}$ reaction II. Experimental and ab-initio studies of the free $\mathrm{Ca} \cdots \mathrm{FCH}_{3}$ complex.
}

\author{
J.-M. Mestdagh, F. Spiegelman*, E. Gloaguen, \\ M. Collier, F. Lepetit, M.-A. Gaveau, C. Sanz Sanz** and B. Soep \\ Laboratoire Francis Perrin (CNRS-URA-2453), \\ DSM/DRECAM/Service des Photons, Atomes et Molécules, \\ C.E.A. Saclay, \\ F-91191 Gif-sur-Yvette cedex, France \\ * Laboratoire de Physique Quantique (UMR 5626 du CNRS), \\ IRSAMC, Université Paul Sabatier, \\ 118 Route de Narbonne, \\ F31062 Toulouse cedex, France \\ ** Unidad Asociada UAM-CSIC, \\ Departamento de Química Física, Facultad de Ciencias C-XIV, \\ Universidad Autónoma de Madrid, 28049 Madrid, Spain. \\ Instituto de Matemáticas y Física Fundamental, \\ C.S.I.C., Serrano 123, 28006 Madrid, Spain.
}

Submitted to J. Phys. Chem A

Version date: April 14, 2006 


\begin{abstract}
The $\mathrm{Ca}^{*}+\mathrm{CH}_{3} \mathrm{~F} \rightarrow \mathrm{CaF}^{*}+\mathrm{CH}_{3}$ reaction was photoinduced in $1: 1 \mathrm{Ca} \cdots \mathrm{CH}_{3} \mathrm{~F}$ complexes formed in a supersonic expansion. The transition state of the reaction was explored by monitoring the electronically excited product, $\mathrm{CaF}$, while scanning the laser that turns on the reaction. Moreover, the electronic structure of the $\mathrm{Ca} \cdots \mathrm{FCH}_{3}$ system was studied using ab-initio methods by associating a pseudopotential description of the $\left[\mathrm{Ca}^{2+}\right]$ and $\left[\mathrm{F}^{7+}\right]$ cores, a core polarization operator on calcium, an extensive Gaussian basis and a treatment of the electronic problem at the CCSD $(\mathrm{T})$ (ground state) and RSPT2 (excited states) level. In this contribution we present experimental results for the free complex and a comparison with the results of a previous experiment where the $\mathrm{Ca} \cdots \mathrm{CH}_{3} \mathrm{~F}$ complexes are deposited at the surface of large argon clusters. The ab-initio calculations allowed an interpretation of the experimental data in terms of two reaction mechanisms, one involving a partial charge transfer state, the other involving the excitation of the $\mathrm{C}-\mathrm{F}$ stretch in the $\mathrm{CH}_{3} \mathrm{~F}$ moiety prior to charge transfer.
\end{abstract}




\section{Introduction}

The present paper is the second of a series [1] concerning the reaction

$$
\mathrm{Ca}+\mathrm{CH}_{3} \mathrm{~F} \rightarrow \mathrm{CaF}+\mathrm{CH}_{3} \quad \Delta \mathrm{H}=-80 \mathrm{~kJ} / \mathrm{mol}=-0.83 \mathrm{eV} .
$$

The energetics are taken from Ref. [2,3]. Since the bonding in CaF is ionic, the mechanism of the reaction could be considered as a simple harpoon reaction where a low ionization energy atom, Ca, transfers one of its valence electron to an electron accepting molecule, $\mathrm{CH}_{3} \mathrm{~F}$. However, a complication arises due to the internal degrees of freedom of $\mathrm{CH}_{3} \mathrm{~F}$ that has motivated our interest to this system. Methyl fluoride is representative of molecules that require deformation to become an electron attractor. No bound state of an additional electron exists at the equilibrium geometry of this molecule and the $\mathrm{C}-\mathrm{F}$ bond has to be stretched, for the molecule to attach an extra electron [4] and become reactive. Hence, the dynamics of the reaction are expected to be more complex than suggested by the simple harpoon model. In particular, the transition state for a reaction to occur in excited electronic states may involve a geometrically wider range of the potential energy surfaces (PES's) than the point like crossing picture usually invoked in the standard harpooning mechanism. Moreover, as in the related $\mathrm{Li}+\mathrm{CH}_{3} \mathrm{~F}$ reaction [5], a barrier is expected to block the ground state reaction 1, although it is exothermic. Evidence of this property has already been shown experimentally in the ground state since a $1: 1$ non reactive $\mathrm{Ca} \cdots \mathrm{CH}_{3} \mathrm{~F}$ complex could be stabilized on a large argon cluster (see paper I of this series [1]).

This class of electron transfer reactions where the molecular reactant needs deformation to attach an extra electron is generally encountered in reactions of alkali and alkaline earth atoms with methyl halide and hydrogen halide molecules. Some of the available literature, both experimental and theoretical is reviewed below. It mostly concerns alkali-hydrogen halides systems.

Experimentally, the dynamics of these reactions has been explored both in bimolecular collisions $[6,7,8]$ and in van der Waals complexes by analyzing action spectra when 
turning on the reaction with lasers and monitoring one of the reaction products. The $\mathrm{Na} / \mathrm{HF}$ [9], Li, Na/HF, $\mathrm{CH}_{3} \mathrm{~F}[10,11,5], \mathrm{Na}_{2} / \mathrm{CH}_{3} \mathrm{Cl}[12], \mathrm{Ca} / \mathrm{HX}[13,14,15,16]$ and $\mathrm{Ba} / \mathrm{CH}_{3} \mathrm{~F}[17,18,19,20,21,22]$ systems were explored using the latter technique. Realtime studies have also been performed on the $\mathrm{Ba} / \mathrm{CH}_{3} \mathrm{~F}$ system $[23,24,25,26,27]$. For all the studies appearing in the literature the observed branching to reaction is quite complex. For example, the Na/HF study reveals that exciting the H-F stretch promotes the electron transfer step prior to reaction [9] and the $\mathrm{Ba} / \mathrm{CH}_{3} \mathrm{~F}$ studies indicate that the reaction proceeds only after the initial electronic excitation has been transferred to a lower electronic state.

Potential and dynamical calculations are also available, essentially for alkali/hydrogen halide systems $[9,28,29,30,31,32,33,34,35,36]$. In particular the Na/HF system has benefited of extensive $a b$ initio energetics and transition dipole moment calculations that yielded an action spectrum in good agreement with the experimental data [35, 36]. Concerning systems that contain an alkaline earth atom, besides the pioneering work of Isaacson and Muckerman on $\mathrm{Ca}+\mathrm{HCl}$ [37], an extensive exploration of the ground state PES is available for Be/HF [38] as well as information on excited PES and the corresponding excited state dynamics for $\mathrm{Ca} / \mathrm{HCl}[39,40,41,42]$ and $\mathrm{Ca}, \mathrm{Ba} / \mathrm{CH}_{3} \mathrm{~F}[40,24]$. The work on $\mathrm{Ca} / \mathrm{CH}_{3} \mathrm{~F}[40]$ is a semiclassical treatment of the dynamics, based on multipolar expansion of the electrostatic interaction between $\mathrm{Ca}$ and $\mathrm{CH}_{3} \mathrm{~F}$. It is aimed at unraveling steric effects in the bimolecular collision between $\mathrm{Ca}\left(4 \mathrm{~s} 3 \mathrm{~d}^{1} \mathrm{D}\right)$ and $\mathrm{CH}_{3} \mathrm{~F}$, spatially oriented.

Process 1 is particularly attractive, given the results published in the first paper of this series, a Cluster Isolated Chemical Reaction (CICR) study where the van der Waals complex $\mathrm{Ca} \cdots \mathrm{CH}_{3} \mathrm{~F}$ is deposited at the surface of a large argon cluster [1]. When scanning the laser to turn the reaction on, a broad structured action spectrum was found. It appears quite blue-shifted, from the $4 \mathrm{~s} 4 \mathrm{p}{ }^{1} \mathrm{P} \leftarrow 4 \mathrm{~s}^{2}{ }^{1} \mathrm{~S}$ calcium resonance transition at $422.8 \mathrm{~nm}$, extending from 360 and $420 \mathrm{~nm}$ where no transition of calcium is expected. In that work it was concluded that a local excitation of the sole calcium 
atom could not account for such a band. Two explanations were proposed, based either on purely electronic or on purely dynamical arguments. The first one implies a significant alteration of the calcium electronic structure that brings a level of calcium within the excitation region. This can be due either to a substantial electron transfer between $\mathrm{Ca}$ and $\mathrm{CH}_{3} \mathrm{~F}$ in the excited state, or to the promotion of the excited electron to a Rydberg orbital, stabilized by the interaction with $\mathrm{CH}_{3} \mathrm{~F}$. The second tentative explanation was invoked due to the observation of structures in the action spectrum, an observation that makes the present $\mathrm{Ca} / \mathrm{CH}_{3} \mathrm{~F}$ system very different from the apparently similar $\mathrm{Ba} / \mathrm{CH}_{3} \mathrm{~F}$ system ( $\mathrm{Ca}$ and $\mathrm{Ba}$ are both alkaline earth atoms) studied in the groups of Ureña $[17,18,19,20,21,22]$ and Radloff $[23,24,25,26,27]$. The structures observed in the $\mathrm{Ca} / \mathrm{CH}_{3} \mathrm{~F}$ system were tentatively assigned to the $\mathrm{C}-\mathrm{F}$ stretch in the $\mathrm{CH}_{3} \mathrm{~F}$ molecule, suggesting that this stretch plays an important role in the dynamics of turning on the reaction. Depositing one (or more) quantum on this vibration would lead to a substantial blue shift of the action spectrum with respect to the calcium resonance line, in agreement with the experiment.

The present work aims at clarifying the issues mentioned above on the nature of the electronic transitions that promote the reaction and on the influence of the dynamics in the observed action spectrum. In particular we would like to know whether the laser excitation directly turns on a charge transfer reaction mechanism. For this purpose, an experimental investigation was achieved, where the $\mathrm{Ca} \cdots \mathrm{CH}_{3} \mathrm{~F}$ complex is "free" instead of being deposited on an argon cluster as in CICR experiments. Our expectation is that the solvation of a charge transfer intermediate by the argon environment of CICR experiments may redshift the corresponding part of the action spectrum. Comparing action spectra from CICR and free cluster experiments would then help to disentangle charge transfer from other reaction paths.

In parallel with the experimental investigation, we have carried out detailed $a b$ initio calculations of the PES's of $\mathrm{Ca}+\mathrm{CH}_{3} \mathrm{~F}$ in the entrance channel, considering all the excited states of calcium up to $\mathrm{Ca}^{*}\left(4 \mathrm{~s} 5 \mathrm{~s}^{1} \mathrm{~S}\right)$. The electronic problem was treated 
within a CASPT2 type scheme within a pseudopotential description of $\mathrm{Ca}$ and F. Moreover, since, as mentioned, charge transfer is expected to play a crucial role, we have also determined the dipole moments of various states along the entrance channel of the reaction.

\section{Experiment}

A full report of the experimental technique will appear in paper III of this series. Briefly, a $\mathrm{He} / \mathrm{CH}_{3} \mathrm{~F} / \mathrm{Ca}$ mixture is expanded into vacuum to generate a supersonic beam containing the $\mathrm{Ca} \cdots \mathrm{CH}_{3} \mathrm{~F}$ complex. Laser evaporation is used to produce $\mathrm{Ca}$ in the gas phase. In addition to the desired complex, the beam contains other compounds: free $\mathrm{Ca}, \mathrm{CH}_{3} \mathrm{~F}$ and $\mathrm{CaF}$ that were generated by the laser ablation of the $\mathrm{Ca}$ rod in the $\mathrm{He} / \mathrm{CH}_{3} \mathrm{~F}$ mixture. The beam also carries clusters of these compounds.

The $\mathrm{Ca} \cdots \mathrm{CH}_{3} \mathrm{~F}$ complex is excited selectively by a pulsed laser (the pump) with a nanosecond pulse width, tuned to absorption bands of the complex. Depending on the wavelength domain, the same laser or a second one (the probe) ionizes the desired compounds resulting from the laser driven reaction (and undesired compounds also present in the beam). The photo-ions are detected using time of flight mass spectrometry. In the present work, the $\mathrm{CaF}^{+}$ion signal is monitored as a function of the pump wavelength. As always, in laser ablation experiments, the choice of expansion conditions, pulse energy and focusing of the ablation laser is quite difficult in order to get a signal originating reliably from reactions within the desired complex. The fluence of the pump laser (and probe laser when two lasers are used) is also of importance in this respect.

The pump laser is tuned over two spectral ranges, 535-421 nm and 415-353 nm, on each side of the $\mathrm{Ca}\left(4 \mathrm{~s} 4 \mathrm{p}{ }^{1} \mathrm{P} \leftarrow 4 \mathrm{~s}^{2}{ }^{1} \mathrm{~S}\right)$ resonant transition at $422.8 \mathrm{~nm}$. The latter spectral range includes the band already reported in our previous CICR experiment [1].

In the red range, the photon energy is not sufficient to allow both for the excitation of the complex and the ionization of the reaction compounds. Ionization is thus 
performed using a second laser, the probe laser, operating at $354.7 \mathrm{~nm}$ and delayed by $5 \mathrm{~ns}$ with respect to the pump laser in order to ascertain that the probe operates on an excited neutral. Energetically, the probe pulses allow us to ionize CaF when excited in the $\mathrm{B}^{2} \Sigma^{+}$state. Recording the corresponding signal while scanning the pump laser provides the so-called action spectra of the reaction forming $\mathrm{CaF}\left(\geq \mathrm{B}^{2} \Sigma^{+}\right)$. As it will appear in paper III of this series, in contrast to signals measured in the blue range (see below), signals measured in the present red range could not be normalized to the concentration of the $\mathrm{Ca} \cdots \mathrm{CH}_{3} \mathrm{~F}$ complex. For this reason, only the overall location and extension of the band observed in this spectral region will be considered below, not its shape and detailed structure.

In the blue range, the photon energy is sufficient to, at once, turn on the reaction in the complex with one photon and further ionize the electronically excited products of the reaction with one or two additional photons. Given the ionization energy of $\mathrm{CaF}$, the ionization can proceed either from a resonant two photon process on $\mathrm{CaF}\left(\mathrm{A}^{2} \Pi\right.$ or $\left.\mathrm{B}^{2} \Sigma^{+}\right)$with a low vibrational energy or from a single photon process on the same electronic states of $\mathrm{CaF}$ but with a substantial vibrational excitation. In both cases, the $\mathrm{CaF}^{+}$signal observed while scanning the laser documents the action spectrum, i. e. the reactive yield of $\mathrm{CaF}(\mathrm{A}, \mathrm{B})$ from excited complex. The ion signals measured here could be normalized to the concentration of the complex since a signal proportional to this concentration was available. Hence, a detailed analysis of structures in the measured spectrum is meaningful. Nevertheless, the shape of the spectrum is not corrected for variations of the ionization efficiency as a function of the CaF internal energy. Potentially this affects the relative intensities of the structures that appear in the spectrum since the internal excitation of CaF may vary from one end of the spectrum to the other. However, this does not affect the localization of the structures, the only question to be addressed in the present paper (a fully corrected spectrum will appear and will be discussed in paper III of this series). 


\section{Calculations}

The calculations have been conducted using the MOLPRO ab initio package [43]. They aim to describe the ground and electronic states of the $\mathrm{Ca} / \mathrm{CH}_{3} \mathrm{~F}$ system as $\mathrm{Ca}$ approaches $\mathrm{CH}_{3} \mathrm{~F}$. A limited exploration of the corresponding PES's along the C-F coordinate is also performed as well as a rough exploration of the topology of the ground state surface.

\subsection{Geometrical considerations}

In the context of the bimolecular reaction 1 the approach between $\mathrm{Ca}$ and $\mathrm{CH}_{3} \mathrm{~F}$ corresponds to the entrance channel of the reaction. We anticipate earlier in the Introduction that, although the ground state reaction forming $\mathrm{CaF}+\mathrm{CH}_{3}$ is exothermic, it is blocked by a barrier. The experimental part of the present work took advantage of this property and indirectly confirmed the existence of such a barrier since it was possible to form a non reactive $\mathrm{Ca} \cdots \mathrm{CH}_{3} \mathrm{~F}$ complex from which the reaction is turned on by photoexcitation. This was observed also in paper I of this series [1]. Hence, a local van der Waals well is expected to exist in the entrance channel of the ground state reaction that defines the equilibrium geometry of the complex. Its location was investigated in the present work, using a geometry optimization at the $\operatorname{CCSD}(\mathrm{T})$ level, corrected for the basis set superposition error (BSSE) with respect to the dissociation channel $\mathrm{Ca}+\mathrm{CH}_{3} \mathrm{~F}$.

The approach between $\mathrm{Ca}$ and $\mathrm{CH}_{3} \mathrm{~F}$ is described in Figure 1 by the distance between Ca and a dummy point $x$. Point $x$ is located along the C-F bond at $1.2 \AA$ from C. For the potential curve calculations, Ca approaches $x$ along a line defined by the $\mathrm{C}-\mathrm{x}$-Ca angle set to $170^{\circ}$. The values $1.2 \AA$ and $170^{\circ}$ are somewhat arbitrary. They were chosen since the corresponding "Ca trajectory" is believed to be representative of an approach towards the $\mathrm{F}$ end of the $\mathrm{CH}_{3} \mathrm{~F}$ molecule. 


\subsection{The electronic problem}

As already mentioned, the present calculations aim at predicting the excited PES's of $\mathrm{Ca} \cdots \mathrm{CH}_{3} \mathrm{~F}$. This implies in particular that the asymptotic energies at large separations between $\mathrm{Ca}$ and $\mathrm{CH}_{3} \mathrm{~F}$ are well predicted, i.e. a correct description of the transition energies energies of calcium are needed here up to $33000 \mathrm{~cm}^{-1}$. For this purpose, we used the technique successfully applied in Ref. [44] where the core electrons of calcium are described by a $\left[\mathrm{Ca}^{2+}\right]$ effective potential, complemented by a core-polarization operator to account for the significant electric dipole polarizability of $\left[\mathrm{Ca}^{2+}\right]\left(\alpha=3.171 \mathrm{a}_{0}^{3}\right)$. The cut-off function used here to calculate the corresponding correction is that of Ref. [45], with the cut-off parameter set to 0.365 a.u.. An extensive uncontracted $[12 \mathrm{~s}, 8 \mathrm{p}, 8 \mathrm{~d}, 4 \mathrm{f}]$ valence Gaussian basis set was used to describe calcium. We shall see below that these choices provide a reliable prediction of the calcium energy levels, up to the $4 \mathrm{~s} 5 \mathrm{~s}^{1} \mathrm{~S}$ levels.

An effective core potential was also used to describe the inner electrons of fluorine $\left(\left[\mathrm{F}^{7+}\right]\right)[46]$ whereas all the electrons of $\mathrm{C}$ and $\mathrm{H}$ were considered. This actually provides an inequivalent treatment of $\mathrm{C}$ and F. Nevertheless, the fact of including explicitly or not the 1s electrons should be of little importance on the present results given that these electrons are anyway kept inactive in the CI treatment (see below). A (7s,7p,4d) contracted into $[6 \mathrm{~s}, 6 \mathrm{p}, 3 \mathrm{~d}]$ basis set was used for $\mathrm{F}$. The $6-311++\mathrm{G}(2 \mathrm{~d}, 2 \mathrm{p})$ and augcc-pvTZ basis sets of Ref. [47] are used for $\mathrm{H}$ and $\mathrm{C}$ respectively. One diffuse $\mathrm{d}$ and one diffuse $\mathrm{f}$ orbital on $\mathrm{C}$ were found necessary to get a reliable $\mathrm{C}-\mathrm{F}$ distance when optimizing the $\mathrm{CH}_{3} \mathrm{~F}$ geometry at large $\mathrm{Ca} \cdots \mathrm{CH}_{3} \mathrm{~F}$ distances.

\subsection{Types of calculations}

Several types of calculations were completed: a) geometry optimization for the ground state of the complex; b) an extensive exploration of the energy variations in the ground and excited states of the complex along the Ca- $x$ approach distance. c) a limited exploration of the PES's when varying the $\mathrm{C}-\mathrm{F}$ distance in $\mathrm{CH}_{3} \mathrm{~F}$ while keeping the 
Ca- $x$ distance and the C- $x$-Ca angle fixed. More details are given now for each of these calculations.

a) The geometry optimization is performed at the $\operatorname{CCSD}(\mathrm{T})$ level for the ground state of the system. It includes the Ca- $x$ distance, the $\mathrm{C}-x$-Ca bending angle, the $\mathrm{C}-\mathrm{H}$ and $\mathrm{C}-\mathrm{F}$ distances and the umbrella angle of $\mathrm{CH}_{3}$. However, it considers $\mathrm{CH}_{3} \mathrm{~F}$ as a regular tetrahedron, with two $\mathrm{H}$-atoms off the $\mathrm{C}-x$-Ca plane by $+60^{\circ}$ and $-60^{\circ}$ and the third one in the C-x-Ca plane. The C-x-Ca angle is defined as shown in Figure 1, with respect to the H-atoms. The optimization completed included a correction for the basis set superposition error as explained in section 5.1.

b) The energy variations for the excited states of the complex were explored as a function of the approach distance $\mathrm{Ca}-x$, the $\mathrm{C}-x$-Ca bending angle being set to $170^{\circ}$. The other coordinates defining the geometry of the system where excited states are to be calculated (i.e. the $\mathrm{C}-\mathrm{H}$ and $\mathrm{C}-\mathrm{F}$ distances and the umbrella angle of $\mathrm{CH}_{3}$ ) are optimized for the ground state at each $\mathrm{Ca}-x$ distance with the $\mathrm{C}-x$-Ca angle set to $170^{\circ}$. As above the ground state calculation is performed at the $\operatorname{CCSD}(\mathrm{T})$ level. In addition to providing geometries for the excited state calculation, this also provides the variation of the $\operatorname{CCSD}(\mathrm{T})$ potential energy along the $\mathrm{Ca}-x$ coordinate. A stateaveraged MCSCF calculation, followed by RSPT2 (precisely the RS2C option of the MOLPRO package $[48,49])$, was performed. The average includes the ten lowest singlet states that correlate adiabatically to the $4 \mathrm{~s}^{2}{ }^{1} \mathrm{~S}, 4 \mathrm{~s} 4 \mathrm{p}{ }^{1} \mathrm{P}, 4 \mathrm{~s} 3 \mathrm{~d}{ }^{1} \mathrm{D}$, and $4 \mathrm{~s} 5 \mathrm{~s}^{1} \mathrm{~S}$ levels of calcium at large $\mathrm{Ca}-\mathrm{CH}_{3} \mathrm{~F}$ distances ${ }^{1}$. The active space consists of two electrons in 13 orbitals (asymptotically the orbitals 4s, 4p, 3d, 5s and 5p of Ca). The relevance of the RSPT2 calculation to describe the atomic excited states can be seen in table 1 where the asymptotic energies at large separation between $\mathrm{Ca}$ and $\mathrm{CH}_{3} \mathrm{~F}$ are compared with the experimental excited energies of free Ca. Since the orbitals are obtained from a state-averaged MCSCF calculation, we do not expect that the weakly bound ground state of the complex, even at the RSPT2 level to be accurate as the

\footnotetext{
${ }^{1}$ Only singlet states are relevant for the comparison with the experimental action spectra since transitions to the triplet states from the singlet ground state are forbidden.
} 
$\operatorname{CCSD}(\mathrm{T})$ calculations mentioned above which have been used to provide information on the ground state.

c) The exploration of the PES's along the C-F coordinates was limited to the vicinity of their minima in the entrance channel, the main goal being to be able to estimate vibrational properties along the $\mathrm{C}-\mathrm{F}$ coordinate.

\section{Experimental results}

The action spectrum observed in the present experiment while monitoring $\mathrm{CaF}$ is shown in Figure 2. It reveals two bands labeled A and B in the figure. Only the spectral region corresponding to band B could be documented in our former CICR experiment due to the limited range achievable using a $c w$ laser to excite the complex [1]. With the purpose of the present paper, the discussion below concentrates on the comparison between band $\mathrm{B}$ of the present action spectrum (free complex) and the band measured in the CICR experiment. Figure 3 present this comparison. A full discussion of the A and $\mathrm{B}$ bands of the free complex action spectrum in Figure 2 is beyond the scope of the present paper. It will appear in paper III of this series.

The similarity between band B and the CICR spectrum presented in Figure 3 is striking, but qualitative. The main features of the CICR spectrum serve as a guideline to examine the similarities and differences between the two spectra. First, the CICR spectrum is structured with three features at $24960,25910,26780 \mathrm{~cm}^{-1}$ respectively. These resolved bands appear blue shifted by $200 \mathrm{~cm}^{-1}$ with respect to corresponding features of the free complex spectrum as indicated by the dashed vertical lines in Figure 3. Additional structures exist in the CICR spectrum, one of which appears as an intense broad shoulder in the blue wing of the central peak near $26100 \mathrm{~cm}^{-1}$. For reasons that will appear in the discussion, we tentatively assign this shoulder in the CICR spectrum to be a red shifted reminiscence of the very structured blue wing of the free complex spectrum. This correspondence is indicated in the figure by dot-dashed Gaussian shaped peaks. The peaks were drawn with the same width, $460 \mathrm{~cm}^{-1}$, in 
both experiments but the CICR peak was red shifted by $650 \mathrm{~cm}^{-1}$ with respect to the corresponding peak in the free complex experiment. Note the width chosen is somewhat arbitrary as it is dependent on the intensity of the peak. However the important point is that the corresponding peak is redshifted when when the complex is solvated on argon whereas the other features are blue shifted.

\section{Calculation results}

\subsection{Optimum geometry in the ground state}

As already mentioned, the optimization is performed at the $\operatorname{CCSD}(\mathrm{T})$ level. It is corrected as it will appear below for the basis set superposition error (BSSE correction). The optimum geometry corresponds to the $\mathrm{Ca}$ atom located near the $\mathrm{F}$ atom of the $\mathrm{CH}_{3} \mathrm{~F}$ molecule in a bent Ca-F-C geometry. It is defined by the distances $\mathrm{Ca}-x=2.67 \AA$, $\mathrm{C}-\mathrm{F}=1.43 \AA$ and $\mathrm{C}-\mathrm{H}=1.09 \AA$, and by the values $220^{\circ}$ and $107^{\circ}$ for the bending angle C- $x$-Ca and the pyramidalization angle of the $\mathrm{CH}_{3}$ group, respectively. This optimum geometry is stabilized by $850 \mathrm{~cm}^{-1}$ with respect to the $\mathrm{Ca}+\mathrm{CH}_{3} \mathrm{~F}$ asymptote. ${ }^{2}$

Of course when the $\mathrm{CH}_{3}$ group is let free to rotate about the $\mathrm{C}-\mathrm{F}$ axis, there is an almost isoergic path corresponding to a circular groove about the axis. In the planar cut to the ground state PES that is defined in Figure 1, the groove appears simply as two quasi degenerate minima at C-x-Ca angles of 140 and $220^{\circ}$. They appear in Figure 4, a cut of the ground state PES along the bending angle $\mathrm{C}$ - $x$-Ca when Ca moves in the plane defined in Figure 1. The squares (fitted by the dashed curve) in the figure were provided by a $\operatorname{CCSD}(\mathrm{T})$ calculation where all the coordinate but the C- $x$-Ca angle were adjusted to minimize the potential energy. Then a BSSE correction is performed using the counterpoise method of Boys and Bernardi for the fragments

\footnotetext{
${ }^{2}$ In preliminary calculations, we have identified a much deeper well on the ground state PES, which corresponds to an inserted structure $\mathrm{FCaCH}_{3}$ connected without any barrier to the $\mathrm{CaF}+\mathrm{CH}_{3}$ asymptote. We can provide an estimate of the dissociation energy, $2.4 \mathrm{eV}$ with respect to $\mathrm{CaF}+\mathrm{CH}_{3}$, i.e. $3.2 \mathrm{eV}$ below the $\mathrm{Ca}+\mathrm{CH}_{3} \mathrm{~F}$ asymptote. It is separated from the present well by a very high barrier that cannot be overcome under the present experimental conditions. Such a deep insertion well has been identified in a $\operatorname{CCSD}(\mathrm{T})$ type investigation of the entire ground state PES of a similar system, Ca/HF [38].
} 
$\mathrm{Ca}$ and $\mathrm{CH}_{3} \mathrm{~F}$ [50]. As observed in the figure, the BSSE correction reduces the depth of the two minima by more than a factor two (745 versus $\left.1677 \mathrm{~cm}^{-1}\right)^{3}$ but does not affect their location. The region of the wells, between 120 and $240^{\circ}$, is indeed the region where the complex is the most compact, hence maximizing the effect of the ghost orbitals.

The two minima that appear in the figure are part of a broad well of $\approx 745 \mathrm{~cm}^{-1}$. Comparatively, the $220 \mathrm{~cm}^{-1}$ barrier between the two minima is significant.

Figure 5 reports ground state potential energy as a function of the approach distance Ca- $x$. The bending angle $\mathrm{C}-x-\mathrm{Ca}$ is set to $220^{\circ}$ in this calculation, which is the $\operatorname{CCSD}(\mathrm{T})$ calculation described in section 3.3b. Again, two results are shown in the figure, whether the BSSE correction is included (solid line and triangles) or not (dashed line and squares). A well depth of $850 \mathrm{~cm}^{-1}$ is found along the BSSE corrected curve, corresponding to the equilibrium geometry of the $\mathrm{Ca} \cdots \mathrm{CH}_{3} \mathrm{~F}$ complex. The BSSE correction reduces the well depth by a factor $2\left(850\right.$ versus $\left.1677 \mathrm{~cm}^{-1}\right)$ but as mentioned in the footnote above it also affects the equilibrium distance $(\mathrm{Ca}-x=2.67 \AA$ along the BSSE corrected curve, versus $2.52 \AA$ without BSSE).

\subsection{Excited potentials along the Ca- $x$ distance}

The excited potentials shown in Figure 6 correlate to the $4 \mathrm{~s} 3 \mathrm{~d}{ }^{1} \mathrm{D}, 4 \mathrm{~s} 4 \mathrm{p}{ }^{1} \mathrm{P}$ and $4 \mathrm{~s} 5 \mathrm{~s}{ }^{1} \mathrm{~S}$ of Ca. They are labeled with their asymptotic correlation as in $\mathrm{C}_{\infty \mathrm{v}}$ since the symmetry lowering due to the non linearity of the Ca-F-C assembly and that due to the presence of the $\mathrm{H}$ atoms is weak. Nevertheless the state labeling is put between quotation marks to stress on the approximate character of the symmetry. The curves labeled " $\Pi$ " and " $\Delta$ " appear doubly degenerated on the scale of the figure whereas they are not rigorously identical in the calculation. The three " $\Sigma$ " curves exhibit severe anti-crossings. In contrast, the two "П" are almost parallel.

The overall shape of curves correlating to $4 \mathrm{~s} 4 \mathrm{p}^{1} \mathrm{P}$ is akin to the potential curves

\footnotetext{
${ }^{3}$ The value of $745 \mathrm{~cm}^{-1}$ is smaller than the stabilization energy of the optimum geometry, $850 \mathrm{~cm}^{-1}$, because the BSSE correction change slightly the Ca- $x$ equilibrium from $2.52 \AA$ where the present calculation is performed to $2.67 \AA$ at the equilibrium geometry.
} 
correlating to $\mathrm{Li}\left(2 \mathrm{p}^{2} \mathrm{P}\right)+\mathrm{CH}_{3} \mathrm{~F}$ that appear in Ref. [5], including the anti-crossing that the upper curve undergoes with a higher $\Sigma$-like curve. In the present case, the $4 \mathrm{~s} 4 \mathrm{p}^{1} \mathrm{P}$ " $\Pi$ " curve is stabilized by $2000 \mathrm{~cm}^{-1}$ with respect to the $4 \mathrm{~s} 4 \mathrm{p}{ }^{1} \mathrm{P}$ asymptote. The well depths of the curves that correlate adiabatically with the $4 \mathrm{~s} 3 \mathrm{~d}{ }^{1} \mathrm{D}$ asymptote are $1530 \mathrm{~cm}^{-1}, 1940 \mathrm{~cm}^{-1}$ and $2910 \mathrm{~cm}^{-1}$, respectively.

To help the discussion on the nature, either valence, Rydberg or charge transfer, of the electronic excited states in the $\mathrm{Ca} \cdots \mathrm{CH}_{3} \mathrm{~F}$ complex, permanent dipole moments were also calculated at the RSPT2 level as a function of the Ca- $x$ distance. Those associated with the molecular states $4 \mathrm{~s}^{2}{ }^{1} \mathrm{~S} " \Sigma ", 4 \mathrm{~s} 4 \mathrm{p}{ }^{1} \mathrm{P} " \Pi ", 4 \mathrm{~s} 4 \mathrm{p}{ }^{1} \mathrm{P} " \Sigma "$ and $4 \mathrm{~s} 5 \mathrm{~s}{ }^{1} \mathrm{~S}$ " $\Sigma "$ are shown in Figure 7. The left panel of the figure shows the projection of these dipole moments along the $\mathrm{C}-\mathrm{F}$ axis. The positive direction is from $\mathrm{F}$ to $\mathrm{C}$, hence the positive dipole values at large Ca- $x$ distance corresponds to $\mathrm{F}^{-\delta} \mathrm{C}^{+\delta}$. The right panel shows the module of these dipoles. Interestingly, the left panel of the figure shows that the projection of the permanent dipole associated with the $4 \mathrm{~s} 4 \mathrm{p}^{1} \mathrm{P} " \Sigma "$ molecular state changes sign and becomes negative at short Ca- $x$ distances.

\subsection{Potentials along the F-C coordinate}

To estimate roughly the vibrational constant for the C-F stretch in both the ground state and excited states, a limited exploration of the PES's was performed as a function of the C-F distance. Figure 8 shows the results for states that are relevant for the discussion, i.e. the ground state and the states correlating adiabatically to $\mathrm{Ca}\left(4 \mathrm{~s} 4 \mathrm{p}^{1} \mathrm{P}_{1}\right)$. Only the $\mathrm{F}$ and $\mathrm{CH}_{3}$ moieties are considered to calculate the reduced mass of the oscillator and get vibrational constants from these curves. This is very approximate, but sufficient for the present purpose given that the C-F bond is much stronger than the $\mathrm{Ca}-\mathrm{CH}_{3} \mathrm{~F}$ one. The resulting $\omega_{\mathrm{e}}$ values is $960 \mathrm{~cm}^{-1}$ for the ground state, and 1065 and $770 \mathrm{~cm}^{-1}$ respectively for the $4 \mathrm{~s} 4 \mathrm{p}^{1} \mathrm{P}_{1} " \Pi "$ and $4 \mathrm{~s} 4 \mathrm{p}{ }^{1} \mathrm{P}_{1} " \Sigma "$ curves. 


\section{Discussion}

\subsection{Electronic structure and geometry of the ground state complex}

The ground state PES cut along Ca- $x$ and BSSE corrected is shown in Figure 5 (solid curve and triangles). As already said, the well of $850 \mathrm{~cm}^{-1}$ that appears at a $2.67 \AA$ Ca$x$ distance, corresponds to a relative minimum of the ground state PES in the entrance channel of the reaction. The actual well depth is probably larger than $850 \mathrm{~cm}^{-1}$ since the counterpoise BSSE correction may be overestimated. Such a deep well depth is consistent with the experimental observation that $\mathrm{Ca} \cdots \mathrm{CH}_{3} \mathrm{~F}$ complexes are easier to form than $\mathrm{Ca} \cdots$ Ar van der Waals complexes. Finally, the calculated well depth is also consistent with observations that will be reported in Paper III of this series where the well depth is bracketed in the range $900-1600 \mathrm{~cm}^{-1}$ from threshold considerations on the complex dissociation.

The equilibrium geometry of the ground state complex at the bottom of the $850 \mathrm{~cm}^{-1}$ well corresponds to a C-F bond length of $1.43 \AA$. This value is longer than the $1.39 \AA$ value calculated for the free $\mathrm{CH}_{3} \mathrm{~F}$ molecule. Notice that the latter value for $\mathrm{CH}_{3} \mathrm{~F}$ is quite close to the experimental value of $1.382 \AA$ [51] and to that of a comparable calculation (1.395 $\AA[23])$. The lengthening of the C-F bond in the complex may be considered as due to some charge transfer from $\mathrm{Ca}$ to $\mathrm{CH}_{3} \mathrm{~F}$, enhancing the negative charge carried by F. However, if not fully excluded, this effect is very small. A simple dipole-induced dipole approximation of the $\mathrm{Ca} \cdots \mathrm{CH}_{3} \mathrm{~F}$ interaction was made indeed, assuming a 1.85 Debye permanent dipole in $\mathrm{CH}_{3} \mathrm{~F}$ as in the free molecule and a $25 \AA^{3}$ polarizability on $\mathrm{Ca}$ as in the free atom [51]. This interaction was used to provide the attractive part of a 6-12 Lennard-Jones potential, the repulsive part being adjusted to reproduce the $2.67 \AA$ equilibrium distance of the complex. As observed in Figure 5 the resulting potential curve (dot dashed curve) is between the BSSE corrected and uncorrected CCSD(T) calculation. Moreover the same dipole-induced dipole model was used in order to estimate the dipole of the complex. It is shown as a dashed curve 
in Figure 5 and compares well with the ab-initio dipole shown in Figure 7.

When running the free complex experiment, the $\mathrm{Ca} \cdots \mathrm{CH}_{3} \mathrm{~F}$ complex is electronically excited from its ground state equilibrium geometry, a simple consequence of the Franck-Condon principle. Accordingly, in the geometry that is relevant to the free complex experiment, the Ca atom rotates almost freely in a cone of $35^{\circ}$ around the $\mathrm{F}$ end of the $\mathrm{CH}_{3} \mathrm{~F}$ molecule. When turning to the CICR experiment where the complex is deposited on an argon cluster, we do not expect that the complex geometry is changed dramatically, except for the $\mathrm{C}-x$-Ca bending angle that is probably fairly blocked inside this cone by the argon environment. This can be anticipated since the Ca-Ar $\left(87 \mathrm{~cm}^{-1}\right.$ [44]) and of $\mathrm{CH}_{3} \mathrm{~F}-\mathrm{Ar}$ (estimated to $\left.200 \mathrm{~cm}^{-1}\right)$ interaction energies are fairly small compared with the $\mathrm{Ca}-\mathrm{CH}_{3} \mathrm{~F}$ binding energy $\left(850 \mathrm{~cm}^{-1}\right)$. This expectation is consistent moreover with the qualitative similarity between the two action spectra shown Figure 3.

\subsection{Assignation of bands $A$ and $B$ in the action spectrum}

The first step in the interpretation is to assign bands A and B of the present action spectrum to specific molecular states of the complex. For this purpose, the action spectrum of Figure 2 is drawn in Figure 9 together with the potential curves of Figures 5 and 6. Doing so, the action spectrum was shifted by $850 \mathrm{~cm}^{-1}$ with respect to that of Figure 2 to account for the energy origin that was chosen to draw the theoretical curves. Of course, this does not take into account the zero point energy in the ground state. This is reasonable however because the zero point energy is due mostly to the $\mathrm{CH}_{3}$ group and is unchanged by the electronic excitation.

Band A of the action spectrum is considered first. With the energy origin of Figure 9 , it covers the range $18400-21600 \mathrm{~cm}^{-1}$. The Frank-Condon region corresponding to the Ca- $x$ distance of $2.67 \AA$ is shown as a vertical line. It crosses the excited potential curves of this energy region at 18830, 19930 and $20484 \mathrm{~cm}^{-1}$. According to the Frank-Condon picture, these values should correspond to maxima in the absorption of the complex. If no dynamical effect forces an additional internal excitation of the 
complex to turn on the reaction, these values should correspond also to maxima in the action spectrum and the two extreme values should determine the range where band A is expected. In fact, the predicted band is located within band A of the action spectrum and is narrower by almost a factor two than that observed experimentally. A part of the discrepancy is probably related to inaccuracies in the calculations that could be in the order of 200 to $400 \mathrm{~cm}^{-1}$. Since experimental uncertainties are also possible as mentioned in section 2 regarding the detailed structure of band A, the dynamics of the reaction associated with the excitation to this band is not discussed further.

Band $\mathrm{B}$ of the action spectrum is examined now. It is structured and covers the range $23800-26800 \mathrm{~cm}^{-1}$ with the energy origin of Figure 9 . It overlaps a region crossed by the potential curves $4 \mathrm{~s} 4 \mathrm{p}{ }^{1} \mathrm{P} " \Sigma$ " and $4 \mathrm{~s} 4 \mathrm{p}{ }^{1} \mathrm{P} " \Pi$ ". Very simply, we assign band B of the action spectrum to transitions towards these molecular states. As already noticed in the result section, these two potential branches show an analogy with those responsible for the $\mathrm{LiF}$ action spectrum in the $\mathrm{Li} \cdots \mathrm{CH}_{3} \mathrm{~F}$ work of Polanyi and coworkers (compare Figure 7 of Ref. [5] to the present Figure 9). However, the detailed comparison between the two action spectra and more specifically the relative location of their most intense features with respect to the relevant potential branches suggests very substantial differences in the dynamics of the two reactions. Hence the question in the present $\mathrm{Ca} \cdots \mathrm{CH}_{3} \mathrm{~F}$ study, is to relate electronic excitations and reactional processes.

\subsection{Reaction mechanisms subsequent to excitation towards band B}

\subsubsection{Partial charge transfer mechanism}

The excitation of the complex in band B corresponds to the Frank-Condon region towards the curves that correlate to $\mathrm{Ca}\left(4 \mathrm{~s} 4 \mathrm{p}^{1} \mathrm{P}\right)$. It is indicated on the vertical line in Figure 9. This suggests two absorption maxima, one at $21520 \mathrm{~cm}^{-1}$ for the intercept with the almost degenerated $\Pi$-like curves and the other at $25500 \mathrm{~cm}^{-1}$ for the intercept with the $\Sigma$-like curve.

The bluer of these maxima, at $25500 \mathrm{~cm}^{-1}$, falls close to the maximum that marks 
the blue edge of band $\mathrm{B}$ in the action spectrum $\left(25700 \mathrm{~cm}^{-1}\right)$. This suggests that the blue part of band B is due to the excitation of the complex towards the " $\Sigma$ " molecular state correlating adiabatically to $\mathrm{Ca}\left(4 \mathrm{~s} 4 \mathrm{p}{ }^{1} \mathrm{P}\right)$. To unravel the corresponding reaction mechanism we need to examine the electronic configuration of this state and its properties in terms of electron localization and dipole moment.

The region of interest along the $4 \mathrm{~s} 4 \mathrm{p}^{1} \mathrm{P}, \Sigma$ curve is the suspended well at $\mathrm{R}_{\mathrm{e}} \approx 2.3 \AA$, the origin of which is better viewed in Figure 6. It is due to an anti-crossing between this curve and the upper $4 \mathrm{~s} 5 \mathrm{~s}^{1} \mathrm{~S}^{\prime \prime} \Sigma^{\prime \prime}$ curve. The two curves exchange their electronic character at the anti-crossing that is located when $\mathrm{Ca}-x \approx 3 \AA$. Hence, the reaction is due to an excitation that promotes the complex towards a state correlating adiabatically to $\mathrm{Ca}\left(4 \mathrm{~s} 4 \mathrm{p}{ }^{1} \mathrm{P}\right)$ and diabatically to $\mathrm{Ca}\left(4 \mathrm{~s} 5 \mathrm{~s}^{1} \mathrm{~S}\right)$. The diabatic correlation indicates a large stabilization, likely related to a substantial electron transfer from excited Ca to $\mathrm{CH}_{3} \mathrm{~F}$. This is substantiated below from general considerations on the permanent electric dipoles shown in Figure 7.

We recall that the value of +2.1 Debye calculated at large $\mathrm{Ca}-x$ separation corresponds to a permanent dipole with $\mathrm{CH}_{3} \mathrm{~F}$ polarized as $\mathrm{F}^{-\delta} \mathrm{C}^{+\delta} \mathrm{H}_{3}$. Two situations can occur when approaching calcium. The first one presumes no electron transfer from Ca to $\mathrm{FCH}_{3}$ and at long distances calcium is simply polarized by the electric field due to the permanent dipole of $\mathrm{FCH}_{3}$. Hence, an additional dipole is centered on calcium, providing the following charge distribution ${ }^{-\delta^{\prime}} \mathrm{Ca}^{+\delta^{\prime}} \cdots \mathrm{F}^{-\delta} \mathrm{C}^{+\delta} \mathrm{H}_{3}$ and the dipole moment of the complex increases as the Ca- $x$ separation is decreased. Of course, the importance of the effect depends on the polarizability of the state of calcium under consideration, which is obviously larger for Rydberg states. However at short distance, in this latter case, the situation is complicated by the fact that one tends towards a complex with an inner $\mathrm{CaCH}_{3} \mathrm{~F}^{+}$core surrounded by the diffuse electron. The dipole is then essentially determined by the shape of the excited electron orbital. The second situation is expected in case of electronic excitation whenever the upper state becomes a charge-transfer state. In this case, the electron distribution may become $\mathrm{Ca}^{+} \mathrm{F}^{-} \mathrm{CH}_{3}$ 
and the dipole moment negative.

Both situations can be observed in Figure 7. Not surprisingly, the transfer-less one is encountered when calcium is in the ground state (curve labeled $4 \mathrm{~s}^{2}{ }^{1} \mathrm{~S}^{\prime \prime} \Sigma^{\prime \prime}$ ). The dipole moment of state $4 \mathrm{~s} 4 \mathrm{p}^{1} \mathrm{P}^{\prime \prime} \Pi^{\prime \prime}$ also appears as transfer-less. Starting from separation, the dipole increases slowly and smoothly for the two states indicating that their electron configuration does not change significantly when $\mathrm{Ca}$ approaches $\mathrm{CH}_{3} \mathrm{~F}$. In contrast, the dipole moments of states $4 \mathrm{~s} 4 \mathrm{p}{ }^{1} \mathrm{P}^{\prime \prime} \Sigma^{\prime \prime}$ and $4 \mathrm{~s} 5 \mathrm{~s}^{1} \mathrm{~S}^{\prime \prime} \Sigma^{\prime \prime}$ do not have a regular behavior. We start with the upper state $4 \mathrm{~s} 5 \mathrm{~s}^{1} \mathrm{~S}^{\prime \prime} \Sigma^{\prime \prime}$. At large Ca- $x$ distances the corresponding dipole is positive, +5 Debye and more, consistent with the Rydberg character and large polarizability associated with $\mathrm{Ca}\left(4 \mathrm{~s} 5 \mathrm{~s}{ }^{1} \mathrm{~S}\right)$. When $\mathrm{Ca}-x \leq 6 \AA$ the dipole along $4 \mathrm{~s} 5 \mathrm{~s}^{1} \mathrm{~S}^{\prime \prime} \Sigma^{\prime \prime}$ looses the asymptotic character and begins to decrease. This is due to an adiabatic mixing with a charge transfer configuration which becomes dominant at shorter distance. In addition, a further change occurs around $3 \AA$, the present state undergoes an anti-crossing with state $4 \mathrm{~s} 4 \mathrm{p}^{1} \mathrm{P}^{\prime \prime} \Sigma^{\prime \prime}$. Hence, the decrease of the dipole moment must be followed (diabatically) on the inner part of latter curve. The dipole goes down to less than -5 Debye indicating a substantial charge transfer character to this state where the system resemble $\mathrm{Ca}^{+} \mathrm{F}^{-} \mathrm{CH}_{3}$. We now discuss the $" \Sigma "$ state dissociating into $4 \mathrm{~s} 4 \mathrm{p}^{1} \mathrm{P}$. From the long distance range its dipole moment remains moderately positive, increasing from +2.1 to +3 Debye. Below the anticrossing region, one may consider that the diabatic extension of the state which is actually the inner part of the $4 \mathrm{~s} 5 \mathrm{~s}^{1} \mathrm{~S}^{\prime \prime} \Sigma^{\prime \prime}$ state. The dipole goes up to +17 Debye and corresponds to a distorted diffuse 5 s electron in the field of the $\mathrm{Ca}^{+} \mathrm{CH}_{3} \mathrm{~F}$ core.

Returning to the reaction mechanism corresponding to excitation towards the suspended well on the adiabatic $4 \mathrm{~s} 4 \mathrm{p}^{1} \mathrm{P}^{\prime \prime} \Sigma^{\prime \prime}$ molecular state. From the above discussion, we know that this molecular state has a significant charge transfer character in the excitation region. Hence, we infer that the corresponding reaction mechanism implies an electron transfer as the initial step. Since the maximum of the action spectrum and that predicted for excitation of the charge transfer state are close together, we 
anticipate that no additional barrier or only a quite weak one has to be overcome when the reaction is initiated by this excitation. However, this does not mean that a direct pathway exists to the reaction. The amount of electron transfer in the excited state may indeed not be sufficient for the system to evolve along a repulsive $\mathrm{CH}_{3}-\mathrm{F}^{-}$coordinate as in a standard harpoon picture. Instead, Figure 8 suggests that the excited system is formed close to a well along the C-F coordinate, implying that a barrier prevents the reaction in this PES. Hence, the barrierless character of the reaction suggests that it proceeds as explained in Ref. [23] for the excited $\mathrm{Ba} \cdots \mathrm{CH}_{3} \mathrm{~F}$ reaction, by an internal conversion to a lower electronic state. This mechanism is named the partial charge transfer mechanism hereafter to make the point that it does not reduce to a simple harpoon picture. A full analysis of this mechanism cannot be done without the simultaneous analysis of the dissociation of the complex as $\mathrm{Ca}+\mathrm{CH}_{3} \mathrm{~F}$. The two processes, reaction and dissociation are indeed competing. Such an analysis is beyond the scope of the present paper and will appear in paper III of this series. The point here is simply the charge transfer character of the excitation.

The partial charge transfer mechanism is actually one of those proposed in ref. [1] to account for the action spectrum in the CICR experiment. With the present discussion it accounts for the blue part of band B in the action spectrum of the free complex and has yet to be disentangled from other contributions. This is performed now as announced in the introduction. Since the excited molecular state involved by this mechanism has a charge transfer character that does not exist in the ground state complex, the corresponding feature in the CICR action spectrum is expected to be red shifted with respect to the corresponding one in the free complex experiment. The analysis suggested by the dot-dashed Gaussian peak in Figure 3 supports this idea: the Gaussian peak defines the blue side of band B in the free complex experiment and with the same width and a red shift of $650 \mathrm{~cm}^{-1}$, it matches the shoulder that appears in the central peak of the CICR spectrum. 


\subsubsection{C-F stretch reaction mechanism}

At this point, the partial charge transfer mechanism accounts for the blue side of band $\mathrm{B}$ in the action spectrum of the free cluster experiment and for a shoulder in the central peak of the CICR experiment. The rest of the two action spectra is thus related to another mechanism, the signature of which is the series of three peaks that appear both in the free complex and the CICR spectra. They are marked by dashed lines in Figure 3, at 24760, 25710 and $26580 \mathrm{~cm}^{-1}$ in the free complex spectrum and blue shifted by $200 \mathrm{~cm}^{-1}$ in the CICR spectrum. The almost equal spacing between the dashed lines suggests a vibrational progression. It was assigned tentatively in Ref. [1] to the C-F stretch.

Inspection of Figure 9 reveals a series of three peaks at 23910, 24860 and $25730 \mathrm{~cm}^{-1}$ respectively. The first band appears between the $\Pi$-like and the $\Sigma$-like potential curves correlating adiabatically to $\mathrm{Ca}\left(4 \mathrm{~s} 4 \mathrm{p}^{1} \mathrm{P}\right)$. Hence, extending the suggestion made in Ref. [1], we assign this series of peaks to the C-F vibrational progression originating in the well of the "П" curve. The latter was calculated to be located at $21515 \mathrm{~cm}^{-1}$ and the $\mathrm{C}-\mathrm{F}$ vibrational frequency to be $1065 \mathrm{~cm}^{-1}$. In that case, the series of peaks would correspond to the excitation of the levels $\mathrm{v}=2,3,4$ of this progression. With this in mind, "experimental" values defining this well can be deduced when fitting the positions of the peaks in the figure. Values of $21300 \mathrm{~cm}^{-1} \omega_{\mathrm{e}}=1120 \mathrm{~cm}^{-1}$ and $\omega_{\mathrm{e}} \mathrm{x}_{\mathrm{e}}=60 \mathrm{~cm}^{-1}$ were found for the well depth, the vibrational constant and the anharmonicity parameter respectively. These values are very close to the calculation, confirming the assignment.

This second reaction mechanisms goes through the direct excitation of the C-F stretch within an electronic excited state that has no electron transfer character, even less than in the ground state of the complex since the dipole moment associated with state $4 \mathrm{~s} 4 \mathrm{p}^{1} \mathrm{~S}^{\prime \prime} \Pi^{\prime \prime}$ has a smaller absolute value than that associated with $4 \mathrm{~s}^{2}{ }^{1} \mathrm{~S}^{\prime \prime} \Sigma^{\prime \prime}$ (see right panel of Figure 7). This suggests that solvation by the argon environment should more effectively stabilize the ground state of the complex than the excited $4 \mathrm{~s} 4 \mathrm{p}^{1} \mathrm{~S}^{\prime \prime} \Pi^{\prime \prime}$ state. Hence the action spectrum is expected to blue shift in the argon environment 
as observed experimentally in Figure 3.

\section{Conclusion}

The present paper is both experimental and theoretical. It is the second of series devoted to the photoinduced reaction forming $\mathrm{CaF}$ in a $1: 1 \mathrm{Ca} \cdots \mathrm{CH}_{3} \mathrm{~F}$ complex. Paper I of this series is a Cluster Isolated Experiment (CICR) where the complex was formed at the surface of a large argon cluster and the reaction turned on by scanning a laser in the vicinity of the calcium resonance line. In the present paper, the complex 1:1 $\mathrm{Ca} \cdots \mathrm{CH}_{3} \mathrm{~F}$ complexes were formed in the pulsed supersonic expansion of a $\mathrm{He} / \mathrm{Ca} / \mathrm{CH}_{3} \mathrm{~F}$ mixture. They are free in the gas phase, i.e. they are not supported by a cluster. As in the CICR experiment, the reaction is turned on by a laser, but over a wide range on both sides of the calcium resonance line. This provided the action spectrum of the photoinduced reaction that gives information on the access to the transition state of the photochemical reaction. Two broad structured bands (named A and B hereafter) were found. They are extending quite far on each side of the calcium resonance line.

The experiment is complemented by $\operatorname{CCSD}(\mathrm{T})$ and RSPT2 ab-initio calculations which provided cuts through the ground and excited singlet PES's of the $\mathrm{Ca} \cdots \mathrm{FCH}_{3}$ system along a $\mathrm{Ca}-\mathrm{CH}_{3} \mathrm{~F}$ separation coordinate. When exploring these surfaces, the ground state of the system was continuously optimized. The ground state PES also benefits of a BSSE correction with respect to the $\mathrm{Ca}+\mathrm{CH}_{3} \mathrm{~F}$ dissociation. The potential curves that are provided accordingly document directly the vertical excitation energies of the complex. A limited exploration of the PES's was performed also along the C-F coordinate, again with an optimization of the other coordinates in the ground state.

The first output of the calculation is a structural information on the ground state of the $\mathrm{Ca} \cdots \mathrm{CH}_{3} \mathrm{~F}$ complex. The latter is slightly bent, with calcium close to the $\mathrm{F}$ end of $\mathrm{CH}_{3} \mathrm{~F}$.

The comparison between the experimental action spectrum and the calculated 
molecular curves helped to assign band A of the action spectrum to the excitation of molecular states that correlate to $4 \mathrm{~s} 3 \mathrm{~d}^{1} \mathrm{D}$ at large separation between $\mathrm{Ca}$ and $\mathrm{FCH}_{3}$, whereas band $\mathrm{B}$ is associated with the molecular states correlating to $4 \mathrm{~s} 4 \mathrm{p}^{1} \mathrm{P}$. Two reaction mechanisms could be discussed for band B. The first one involves a partial electron transfer from $\mathrm{Ca}$ to $\mathrm{CH}_{3} \mathrm{~F}$. However it cannot be reduced to a simple harpooning process since the excited complex is not expected to dissociate directly as $\mathrm{CaF}+\mathrm{CH}_{3}$. Instead, an internal conversion is likely to occur prior to reaction. In this respect, the $\mathrm{Ca} / \mathrm{CH}_{3} \mathrm{~F}$ system is akin to the $\mathrm{Ba} / \mathrm{CH}_{3} \mathrm{~F}$ studied in the group of Radloff and that of Ureña. No such electron transfer is implied in the second reaction mechanism that involves the deposition of two or more vibrational quanta in the C-F stretch in addition to the electronic excitation. The electron transfer that eventually promotes the reaction likely proceeds in a later step of the reaction, through an intermediate not directly accessible by vertical excitation from the ground state of the complex.

The above analysis provides a partial understanding of the excited $\mathrm{Ca}+\mathrm{CH}_{3} \mathrm{~F}$ reaction but further works are needed to get a full picture of the excited state dynamics of this system. We already mentioned that paper III of this series is going to examine the competition between the present reaction channel and the $\mathrm{Ca}+\mathrm{CH}_{3} \mathrm{~F}$ dissociation channel of the complex. A real time experiment that probes the exit channel of the reaction, far from the Franck Condon region of the reaction is also planned in order to get information on the apparently late charge transfer step that promotes the reaction. Finally, thorough PES's calculations are currently underway to allow for wavepacket propagation, a challenge at the moment, given the number of PES's coupled and the number of degrees of freedom expected to play a role in the dynamics.

\section{Acknowledgments}

Partial support is acknowledged from CNRS-GDR 2758 : "Agrégation, Fragmentation Thermodynamique de Systèmes Complexes Isolé ", from the Spanish-French bilateral grant Picasso-no 09252TM and from the European Community through the PICNIC 
network (Product Imaging and Correlation: Non-adiabatic Interactions in Chemistry) under contract number HPRN-CT-2002-00183.

\section{References}

[1] M. A. Gaveau, E. Gloaguen, P. R. Fournier, and J. M. Mestdagh, J. Phys. Chem. A 109, 9494 (2005).

[2] Karny and R. N. Zare, J. Chem. Phys. 68, 3360 (1978).

[3] R. C. Weast, M. J. Astle, and W. H. Beyer, Handbook of Chemistry and Physics, $65^{\text {th }}$ edition 1984-1985., CRC, Boca Raton, Florida, 1984.

[4] P. Piecuch, J. Mol. Struct. 436-437, 503 (1997).

[5] A. J. Hudson, F. Y. Naumkin, H. B. Oh, J. C. Polanyi, and S. A. Raspopov, Faraday Discuss. 118, 191 (2001).

[6] M. H. M. Janssen, D. H. Parker, and S. Stolte, J. Phys. Chem. 95, 8142 (1991).

[7] A. E Wiskerke, S. Stolte, H. J. Loesch, and R. D. Levine, Phys. Chem. Chem. Phys. 2, 757 (1999).

[8] D. Husain, J. F. Geng, F. Castano, and M. N. S. Rayo, J. Photochem. Photobiol. A-Chem. 133, 1 (2000).

[9] X. Y. Chang, R. Ehlich, A. J. Hudson, P. Piecuch, and J.C. Polanyi, Faraday Discuss. 108, 411 (1997).

[10] X. Y. Chang, R. Ehlich, A. J. Hudson, J.C. Polanyi, and J. X. Wang, J. Chem. Phys. 106, 3988 (1997).

[11] A. J. Hudson, H. B. Oh, J. C. Polanyi, and P. Piecuch, J. Chem. Phys. 113, 9897 (2000).

[12] K. Liu, J. C. Polanyi, and S. Yang, J. Chem. Phys. 96, 8628 (1992).

[13] J. P. Visticot, B. Soep, and C. J. Whitham, J. Phys. Chem. 92, 4574 (1988). 
[14] B. Soep, C. J. Whitham, A. Keller, and J. P. Visticot, Faraday Discuss. 91, 191 (1991).

[15] L. Krim, P. Qiu, C. Jouvet, C. Lardeux-Dedonder, J. G. McCaffrey, B. Soep, D. Solgadi, O. Benoist d'Azy, P. Ceraolo, and et al., Chem. Phys. Lett. 200, 267 (1992).

[16] A. Keller, R. Lawruszczuk, B. Soep, and J. P. Visticot, J. Chem. Phys. 105, 4556 (1996).

[17] S. Skowronek, R. Pereira, and Angel González Ureña, J. Chem. Phys. 107, 1668 (1997).

[18] S. Skowronek, R. Pereira, and Angel González Ureña, J. Phys. Chem. 101, 7468 (1997).

[19] S. Skowronek and A. González Ureña, Prog. React. Kinet. Mech. 24, 101 (1999).

[20] S. Skowronek, Jiménez J. B., and A. González Ureña, Chem. Phys. Lett. 303, 275 (1999).

[21] V. Stert, P. Farmanara, W. Radloff, F. Noack, S. Skowronek, Jiménez J., and A. González Ureña, Phys. Rev. A 59, R1727 (1999).

[22] V. Stert, P. Farmanara, H.-H. Ritze, W. Radloff, and A. Gonzalez-Ureña, Chem. Phys. Lett. 337, 299 (2001).

[23] V. Stert, H. H. Ritze, P. Farmanara, and W. Radloff, Phys. Chem. Chem. Phys. 3, 3939 (2001).

[24] V. Stert, H. H. Ritze, W. Radloff, K. Gasmi, and A. Gonzalez-Ureña, Chem. Phys. Lett. 355, 449 (2002).

[25] V. Stert, H. H. Ritze, and W. Radloff, Chem. Phys. Lett. 354, 269 (2002).

[26] H. Lippert, J. Manz, M. Oppel, G. K. Paramonov, W. Radloff, H. H. Ritze, and V. Stert, Phys. Chem. Chem. Phys. 6, 4283 (2004).

[27] H. Lippert, J. Manz, M. Oppel, G. K. Paramonov, W. Radloff, H. H. Ritze, and V. Stert, Phys. Chem. Chem. Phys. 6, 5086 (2004). 
[28] M. Paniagua, A. Aguado, M. Lara, and O. Roncero, J. Chem. Phys. 111, 6712 (1999).

[29] V. Spirko, P. Piecuch, and O. Bludsky, J. Chem. Phys. 112, 189 (2000).

[30] F. Mrugala, P. Piecuch, V. Spirko, and O. Bludsky, J. Mol. Struct. 555, 43 (2000).

[31] A. W. Jasper, M. D. Hack, A. Chakraborty, D. G. Truhlar, and P. Piecuch, J. Chem. Phys. 115, 7945 (2001).

[32] A. W. Jasper, M. D. Hack, D. G. Truhlar, and P. Piecuch, J. Chem. Phys. 116, $8353(2002)$.

[33] R. Burcl, P. Piecuch, V. Spirko, and O. Bludsky, Theochem-J. Mol. Struct. 591, $151(2002)$

[34] A. W. Jasper, M. D. Hack, A. Chakraborty, D. G. Truhlar, and P. Piecuch, J. Chem. Phys. 119, 9321 (2003).

[35] M. S. Topaler, D. G. Truhlar, X. Y. Chang, P. Piecuch, and J. C. Polanyi, J. Chem. Phys. 108, 5349 (1998).

[36] M. S. Topaler, D. G. Truhlar, X. Y. Chang, P. Piecuch, and J. C. Polanyi, J. Chem. Phys. 108, 5378 (1998).

[37] A. D. Isaacson and J. T. Muckerman, J. Chem. Phys. 73, 1729 (1980).

[38] M. J. McGuire, P. Piecuch, K. Kowalski, S. A. Kucharski, and M. Musial, J. Phys. Chem. A 108, 8878 (2004).

[39] M. De Castro, R. Candori, F. Pirani, V. Aquilanti, M. Garay, and A. González Ureña, J. Chem. Phys. 112, 770 (2000).

[40] A. J. H. M. Meijer, G. C. Groenenboom, and A. van der Avoird, J. Chem. Phys. 105, 2247 (1996).

[41] C. Sanz, A. van der Avoird, and O. Roncero, J. Chem. Phys. 123 (2005).

[42] G. Verbockhaven, C. Sanz, G. C. Groenenboom, O. Roncero, and A. van der Avoird, J. Chem. Phys. 122 (2005). 
[43] H.-J. Werner and P. J. Knowles, MOLPRO a package of ab initio programs, version 2005, http://www.molpro.net, 2005.

[44] F. Spiegelman, L. Maron, W. H. Breckenridge, J. M. Mestdagh, and J. P. Visticot, J. Chem. Phys. 117, 7534 (2002).

[45] P. Fuentealba, H. Stoll, and A. Savin, Physical Review A General Physics 38, 483 (1988).

[46] Y. Bouteiller, C. Mijoule, M. Nizam, J. C. Barthelat, J. P. Daudey, M. Pelissier, and B. Silvi, Molecular Physics 65, 295 (1988).

[47] Pacific Northwest National Laboratory, Gaussian Basis Set Library, http://www.cse.clrc.ac.uk/qcg/basis/, 2005.

[48] P. Celani and H. J. Werner, J. Chem. Phys. 112, 5546 (2000).

[49] H.-J. Werner, Mol. Phys. 89, 645 (1996).

[50] S. F. Boys and F. Bernardi, Mol. Phys. 19, 553 (1970).

[51] D.R. Lide (Ed.), Handbook of Chemistry and Physics, ryth edition, CRC, Boca Raton, Florida, 1996.

[52] J. Sugar and C. Corliss, J. Phys. Chem. Ref. Data 8, 865 (1979).

[53] E. Czuchaj, M. Krosnicki, and H. Stoll, Chem. Phys. 292, 101 (2003). 


\begin{tabular}{|c|c|c|c|}
\hline $\begin{array}{c}\text { Ca } \\
\text { level }\end{array}$ & $\begin{array}{c}\text { Present } \\
\text { calculation }\end{array}$ & $\begin{array}{c}\text { Experiment } \\
{[52]}\end{array}$ & $\begin{array}{c}\text { Calculation } \\
\text { of Ref. [53] }\end{array}$ \\
\hline $4 s 4 p^{3} P$ & 14626 & 15263 & 15121 \\
$4 s 3 d^{3} D$ & 20328 & 20356 & 20620 \\
$4 s 3 d^{1} D$ & 21547 & 21849 & 21965 \\
$4 s 4 p^{1} P$ & 23440 & 23652 & 23434 \\
$4 s 5 s^{3} S$ & 31541 & 31539 & \\
$4 s 5 s{ }^{1} S$ & 33281 & 33317 & \\
\hline
\end{tabular}

Table 1: Atomic term energies for $\mathrm{Ca}\left(\mathrm{in}_{\mathrm{cm}}^{-1}\right)$. The experimental values are $j$ averaged. 


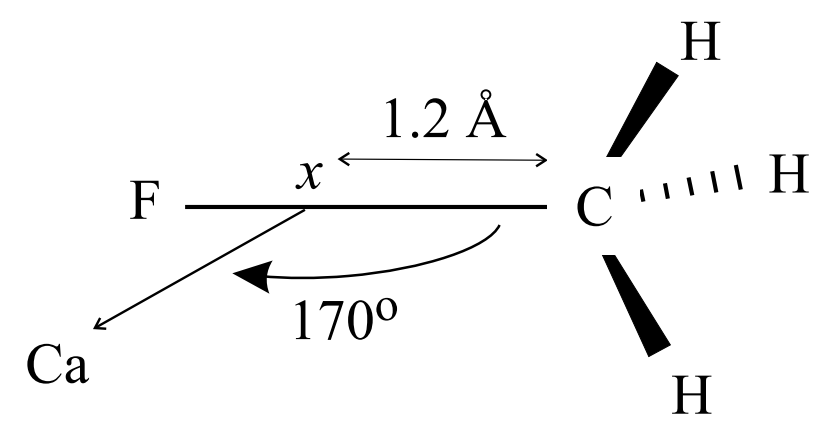

Figure 1: Geometry of the $\mathrm{Ca} \cdots \mathrm{CH}_{3} \mathrm{~F}$ complex used for the potential energy calculations reported in Figures 5 and 6. 


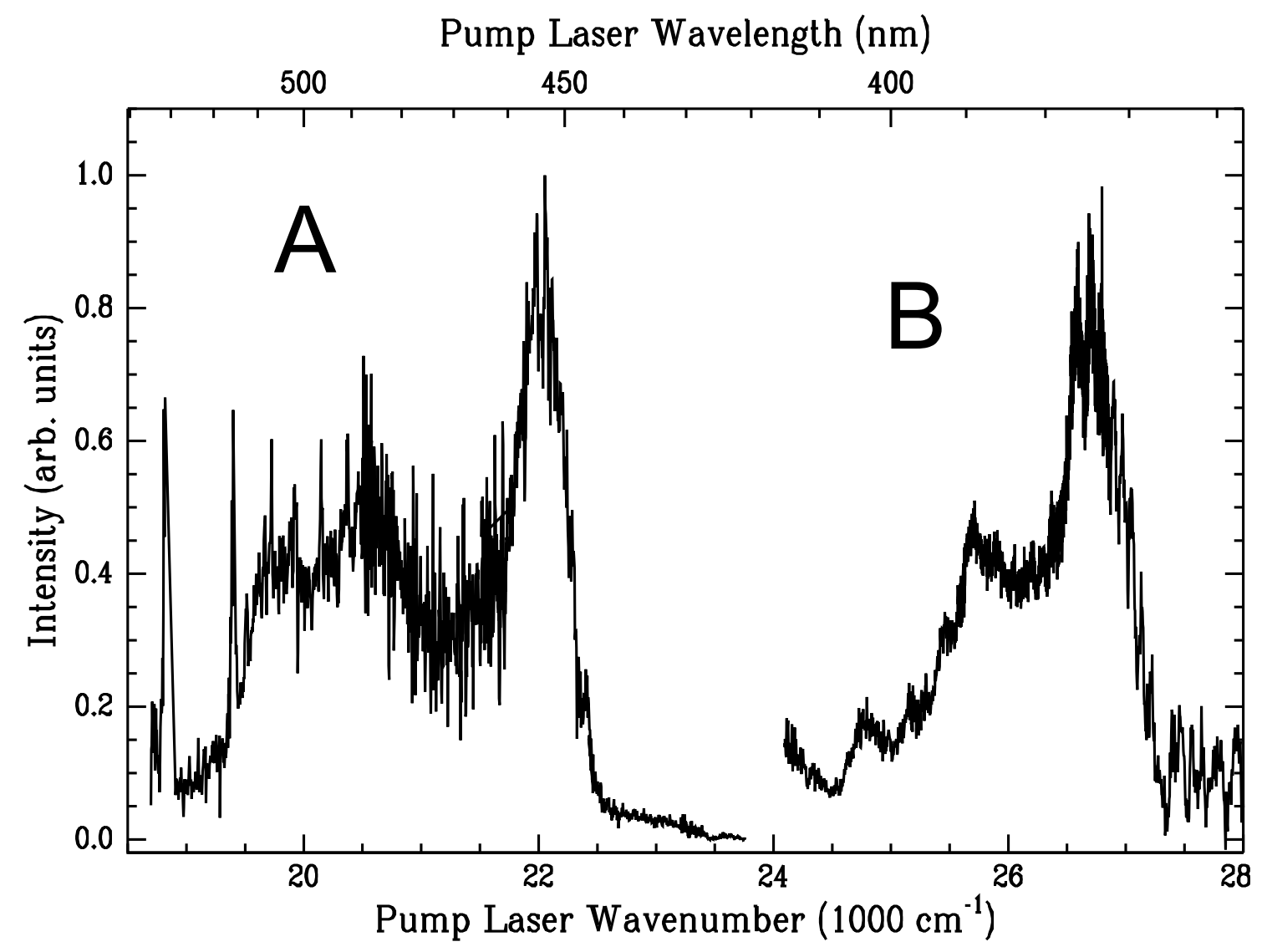

Figure 2: Action spectrum for producing electronically excited $\mathrm{CaF}$ in a 1:1 $\mathrm{Ca} \cdots \mathrm{CH}_{3} \mathrm{~F}$ complex. 


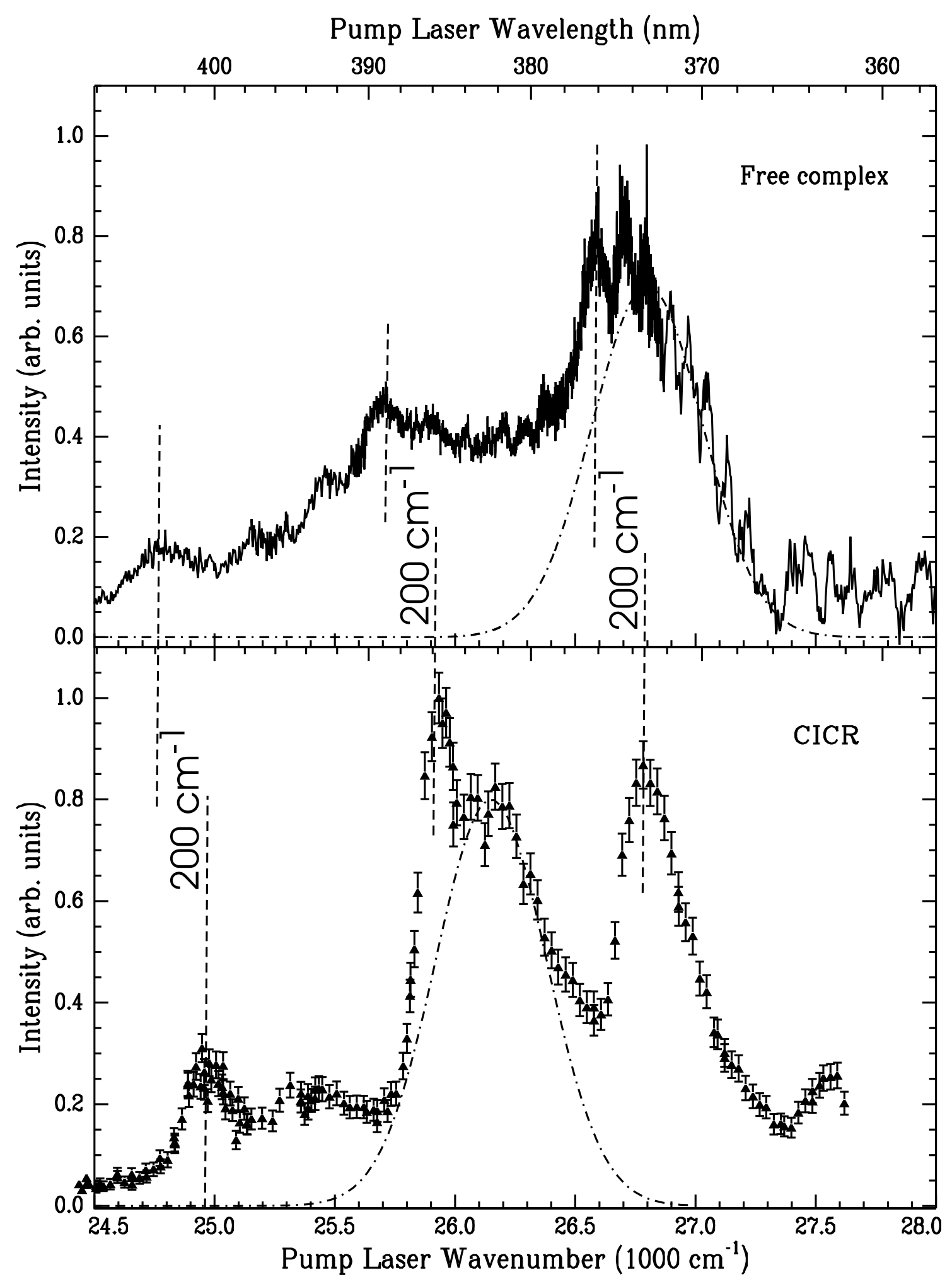

Figure 3: Band B of the action spectrum shown in Figure 2 (top panel). The bottom panel recalls the action spectrum measured in a previous CICR experiment where the $\mathrm{Ca} \cdots \mathrm{CH}_{3} \mathrm{~F}$ complex is deposited at the surface of a large argon cluster and $\mathrm{CaF}(\mathrm{A}, \mathrm{B})$ monitored by its fluorescence [1]. The dotted dashed Gaussian curves are plotted to help the discussion. 


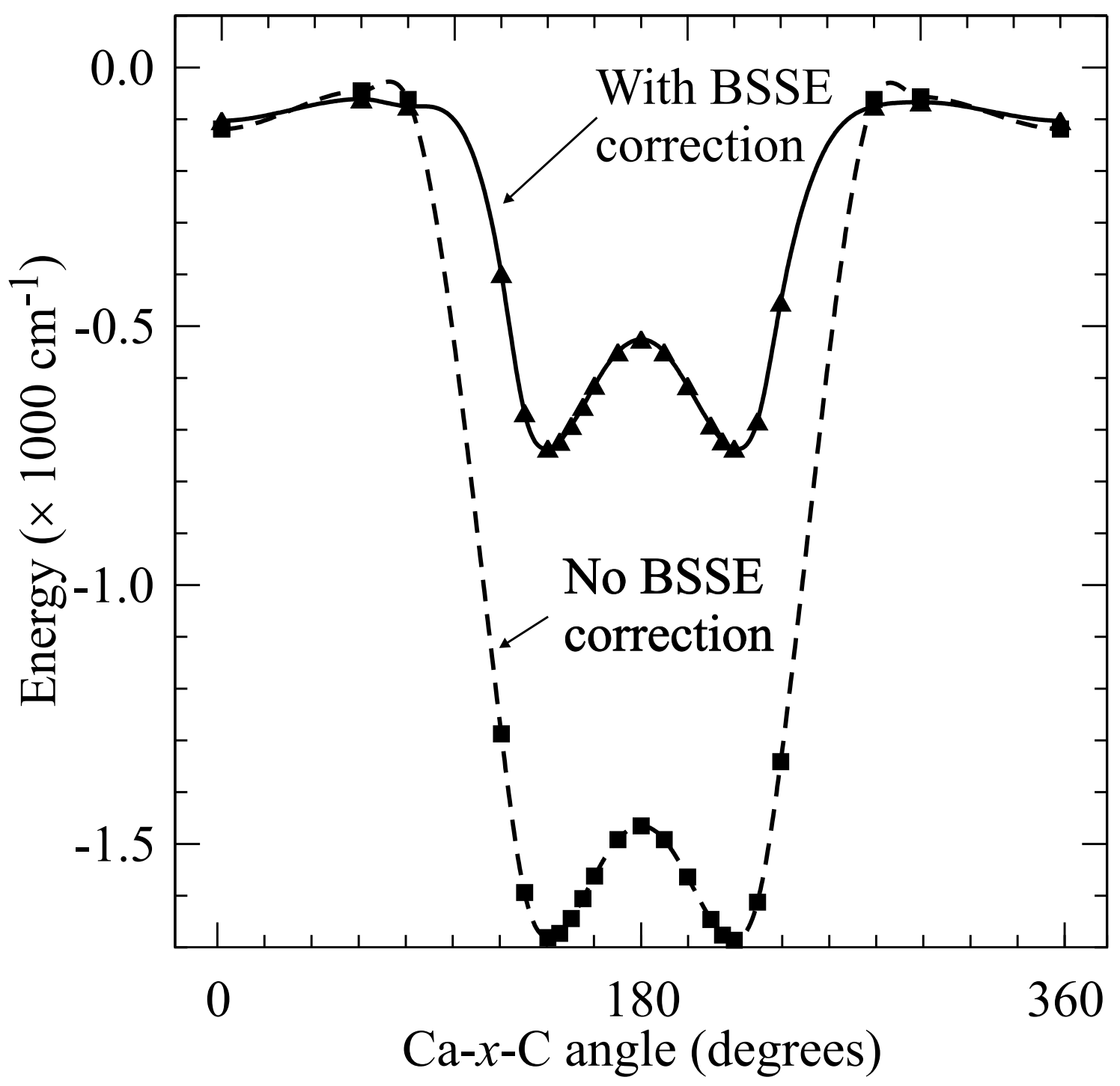

Figure 4: Calculation of the $\mathrm{Ca} \cdots \mathrm{CH}_{3} \mathrm{~F}$ ground state at the $\mathrm{CCSD}(\mathrm{T})$ level with the geometry optimization described in the text. The ground state energy (full triangles and solid line) is shown as a function of the bending angle $\mathrm{C}$ - $x$-Ca after correction for the BSSE (see the text). The dashed curve (and squares) shows the BSSE uncorrected curve. The origin of the energies corresponds to the dissociation of the complex as $\mathrm{Ca}\left(4 \mathrm{~s}^{2}{ }^{1} \mathrm{~S}_{0}\right)+\mathrm{CH}_{3} \mathrm{~F}$. 


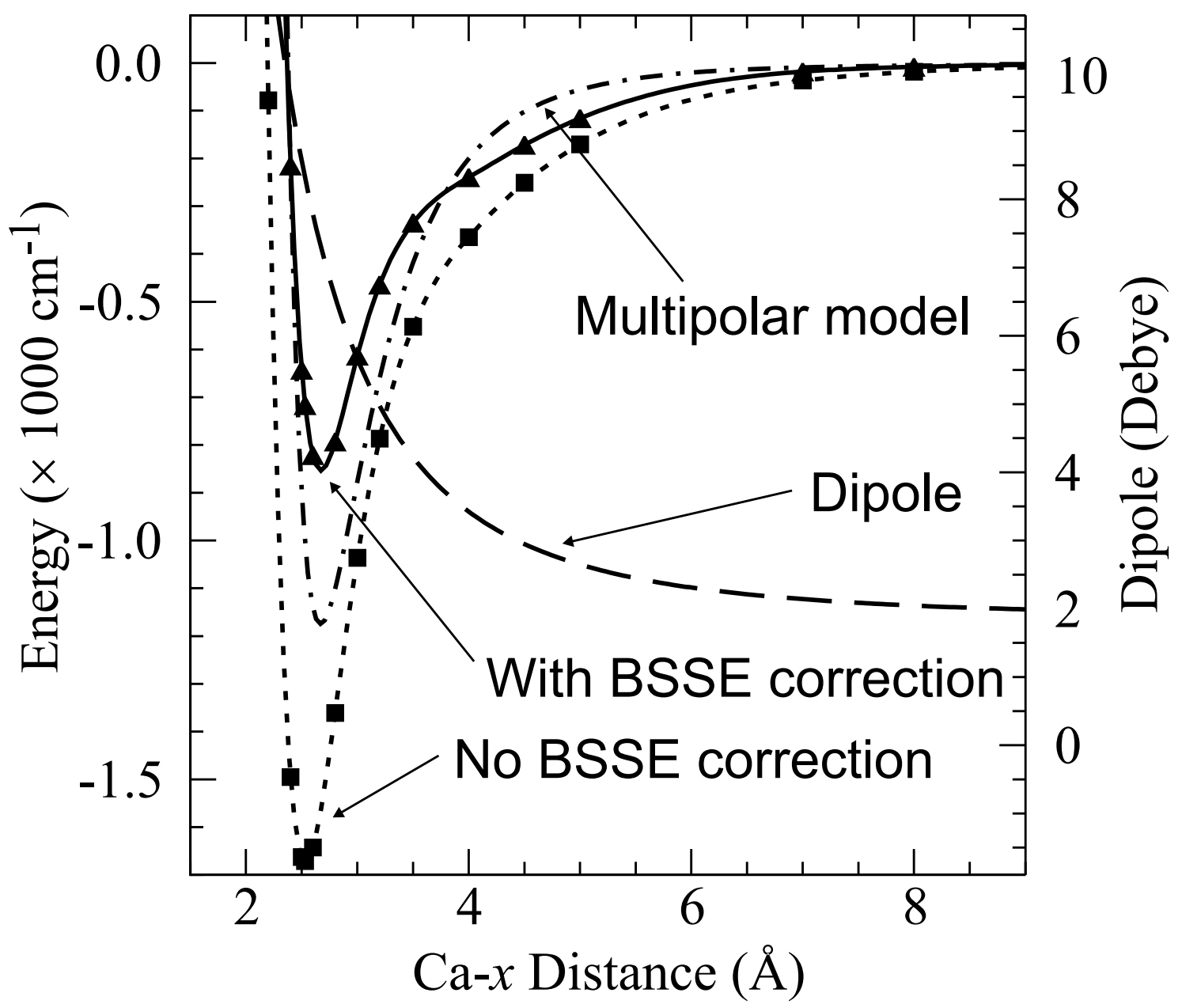

Figure 5: Same as Figure 4 but the ground state energy is shown as a function of the Ca- $x$ distance. The full curve and triangles correspond to BSSE corrected potential energies, whereas the dashed curve and squares show uncorrescted energies. The dotted-dashed and dashed lines refer respectively to the energy and dipole calculations in the multipolar interaction model discussed in section 6 . 


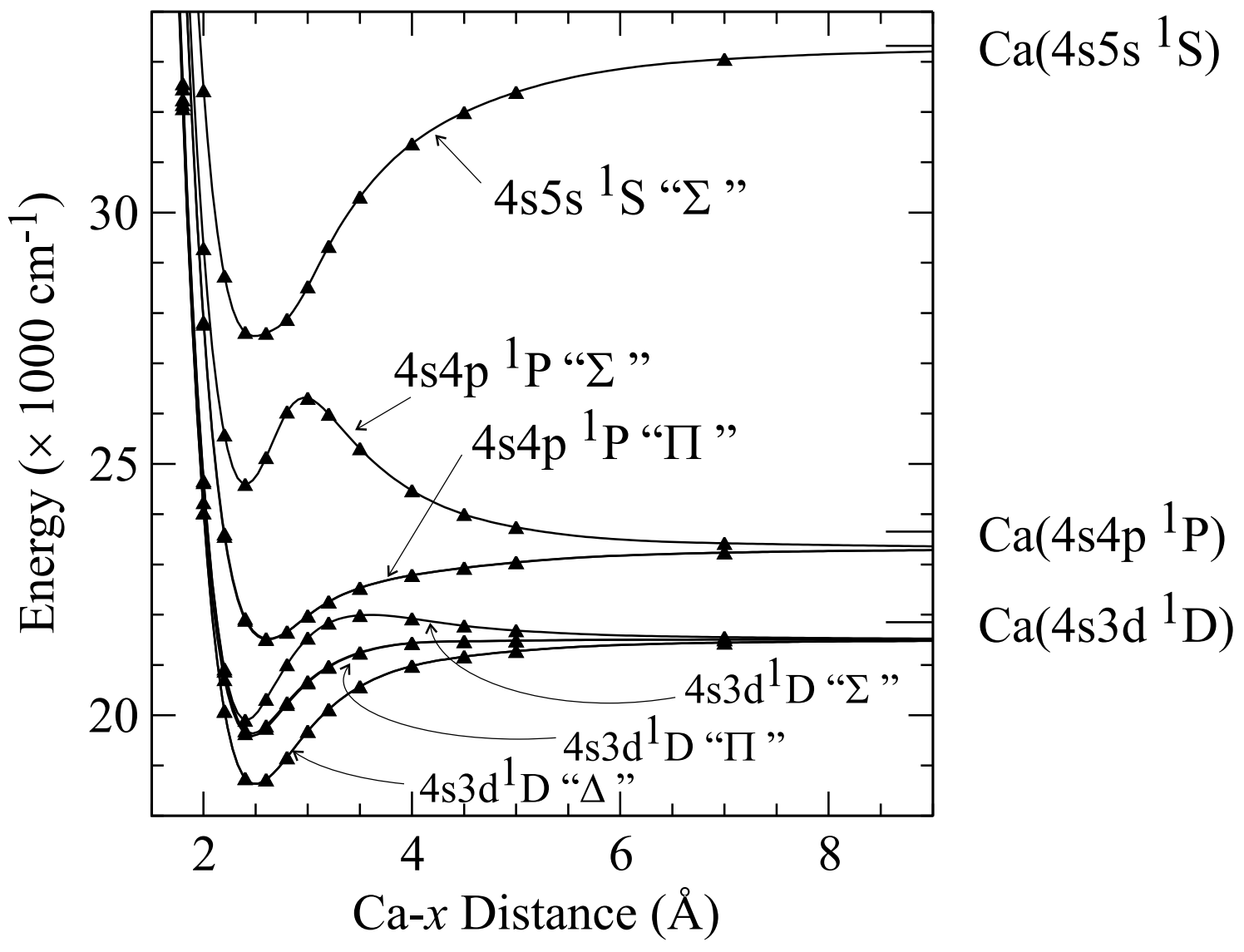

Figure 6: Same as Figure 5 for the excited singlet state calculation at the RSPT2 level as a function of the Ca- $x$ distance. The labels giving asymptotic energy levels are placed at their experimental values. 


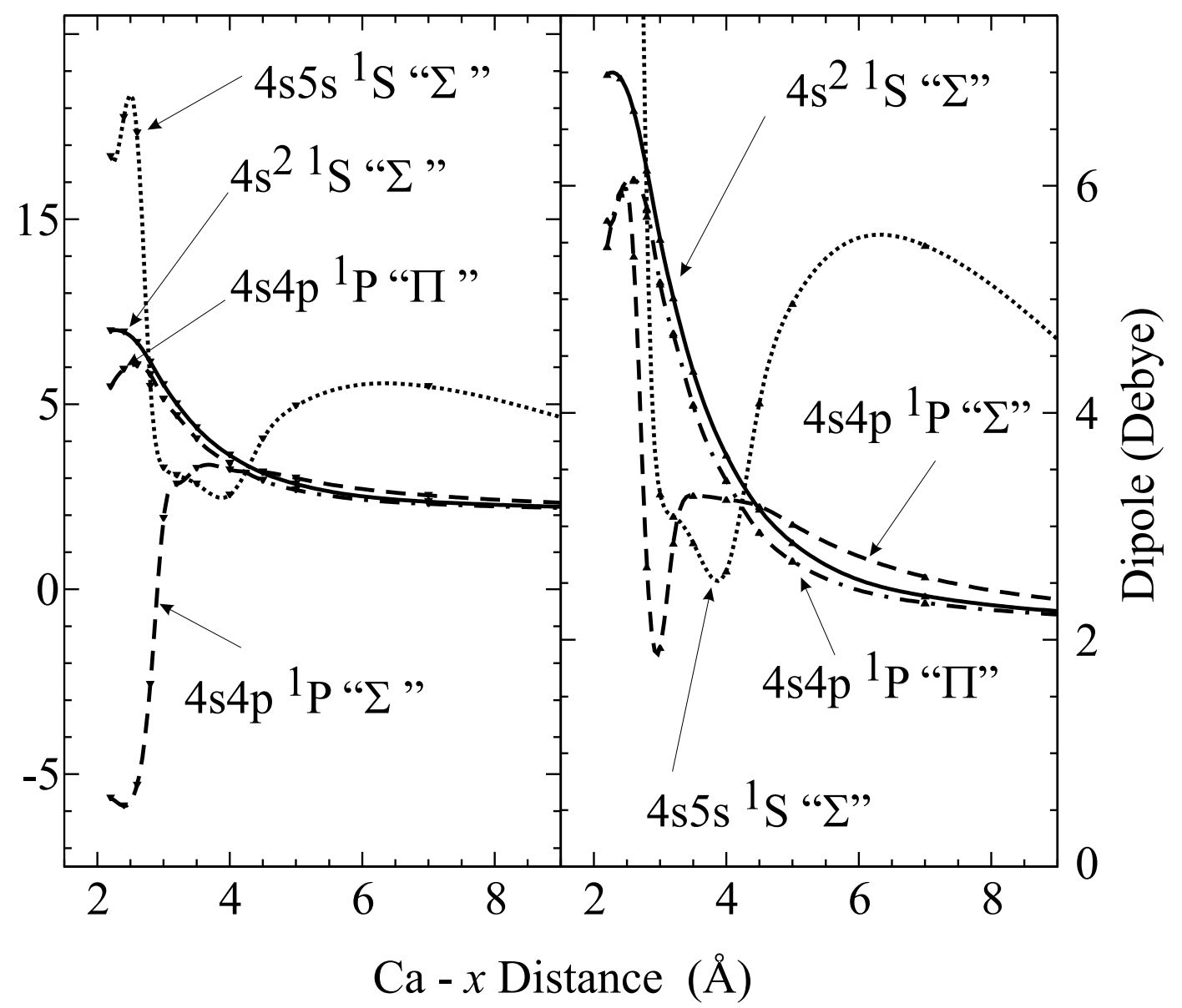

Figure 7: Permanent dipole moment of various electronic states of the $\mathrm{Ca} \cdot \mathrm{CH}_{3} \mathrm{~F}$ complex (as labeled in the figure) as a function of the Ca- $x$ distance. The left panel shows the projection of the dipoles along the F-C axis, the positive direction being from $\mathrm{F}$ to $\mathrm{C}$. The right panel show the module of the dipole. 


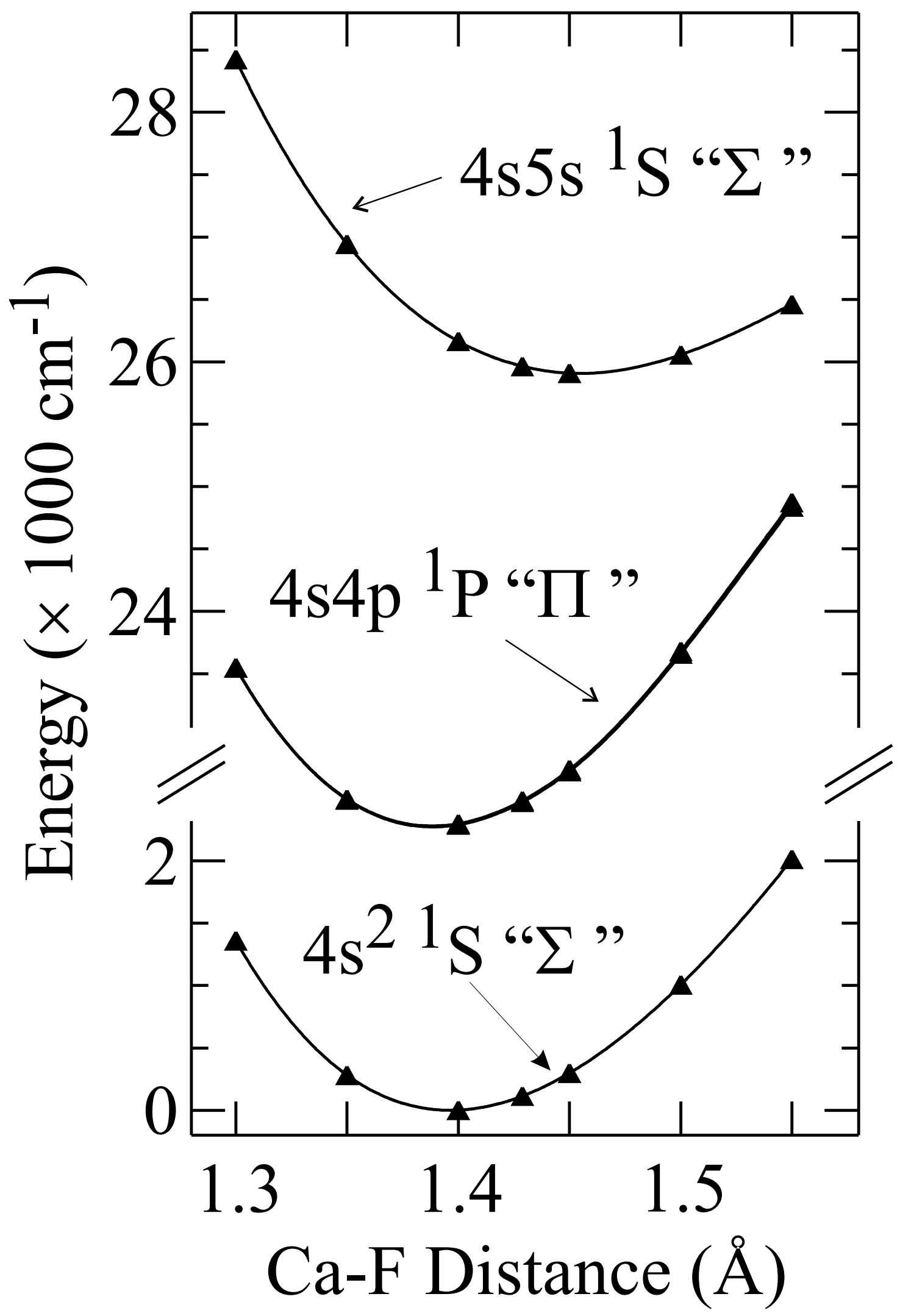

Figure 8: Potential energies at the MCSCF level as a function of the C-F distance for various electronic states of the $\mathrm{Ca} \cdots \mathrm{CH}_{3} \mathrm{~F}$ complex (as labeled in the figure). 


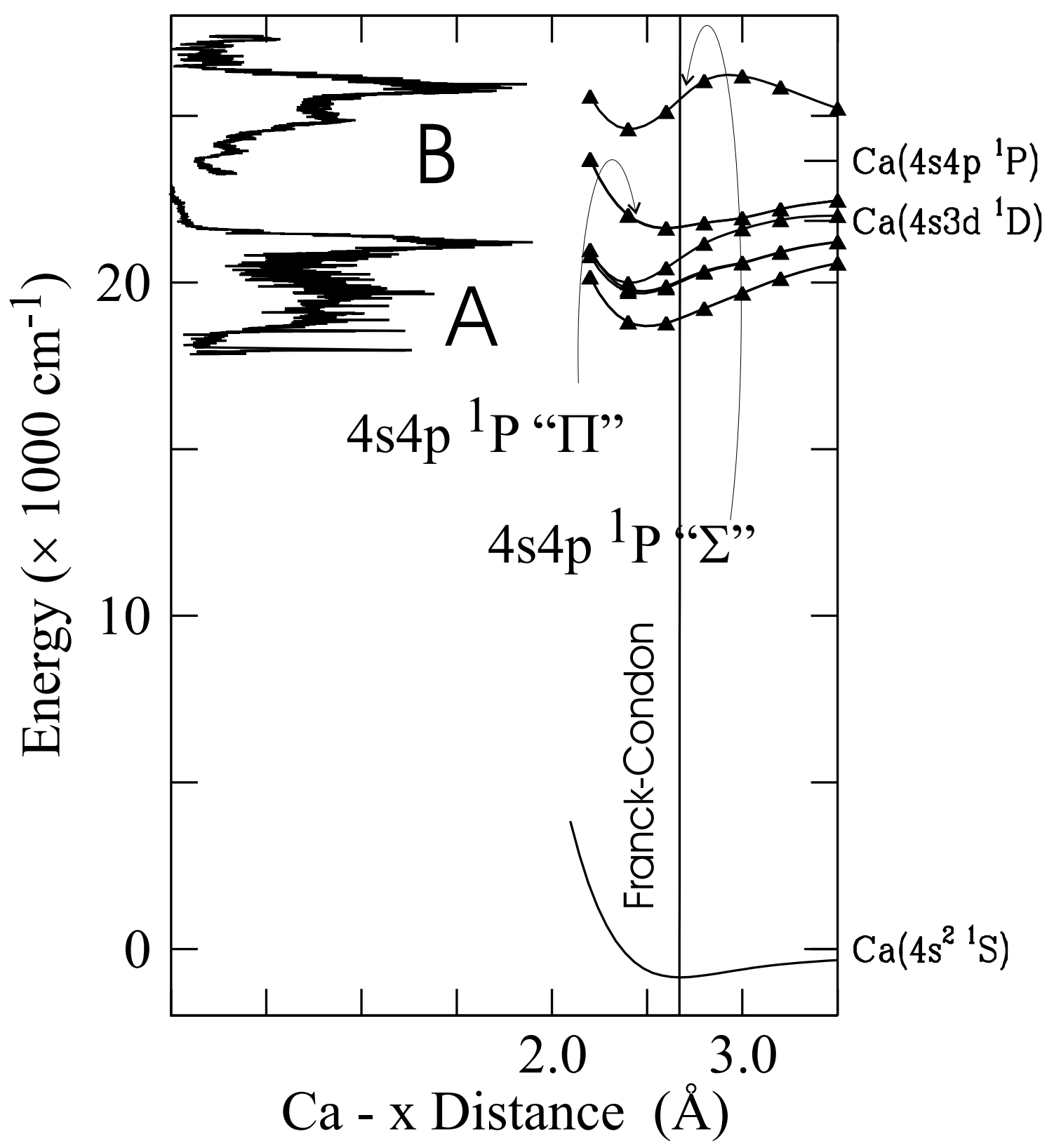

Figure 9: Compilation of the experimental results of Figures 2 with the theoretical potentials of Figures 5 (BSSE corrected) and 6. The energy origin is that of Figures 5 and 6 and the experimental spectrum is shifted accordingly (see text). 